\title{
A NOTE ON THE ATTACHMENT OF THE WASP, BEMBIX NUBILIPPENNIS, TO THEIR NESTING SITES
}

\author{
By PhIL RAU \\ Kirkwood, Mo.
}

In "Wasp Studies Afield" in 1917 I describe the nesting behavior of Bembix nubilipennis. The wasps have emerged year after year in early summer, and then have dug their new tunnels in the same site where they were born, in this instance the hard-baked barren soil of a baseball diamond. This gave me at that time an opportunity to study four successive generations of these wasps in as many years.

Dr. Wm. M. Wheeler in his introduction to the above work especially calls attention to the strong attachment of these wasps to their nesting site, for they keep to the same locality for generation after generation. "Such a habit," says Dr. Wheeler, "has the ear-marks of great antiquity, and seems to indicate that the present type of nesting site is like the one in which the group originated." This statement has caused me often to visit this site over a period of years, to see how long they would maintain this colony. The colony was first observed in a vacant lot in the heart of southwest St. Louis in 1914 (loco citato pp. 1-36) and today, twenty years later, the colony is nesting in the same way in the same site. They have not spread to the surrounding grass plots or to a roadway nearby; the population has not diminished with the passing of the years, and neither has the population increased during this period. There is one slight variation, however, in that a portion of the population has wandered away and become colonized in a second and smaller baseball diamond two hundred feet away. This smaller diamond was made ten years ago, and I watched it yearly to note any Bembix migration. I felt the site was suitable for Bembix, and it would be only a matter of time before they would become established. The new barren 
area was not adopted until the seventh year of its existence, and now after four years it has only about twenty burrows of this wasp, whereas several hundred may be counted on the older diamond.

Thus we see that not only do Bembix stay on one site generation after generation, but many years are likely to elapse before certain mothers turn their attention to an attractive area just within a stone's throw of their old home. Dr. Wheeler's conclusion is probably correct when he says that the species shows its archaic origin by its nesting habits. 



Submit your manuscripts at

http://www.hindawi.com
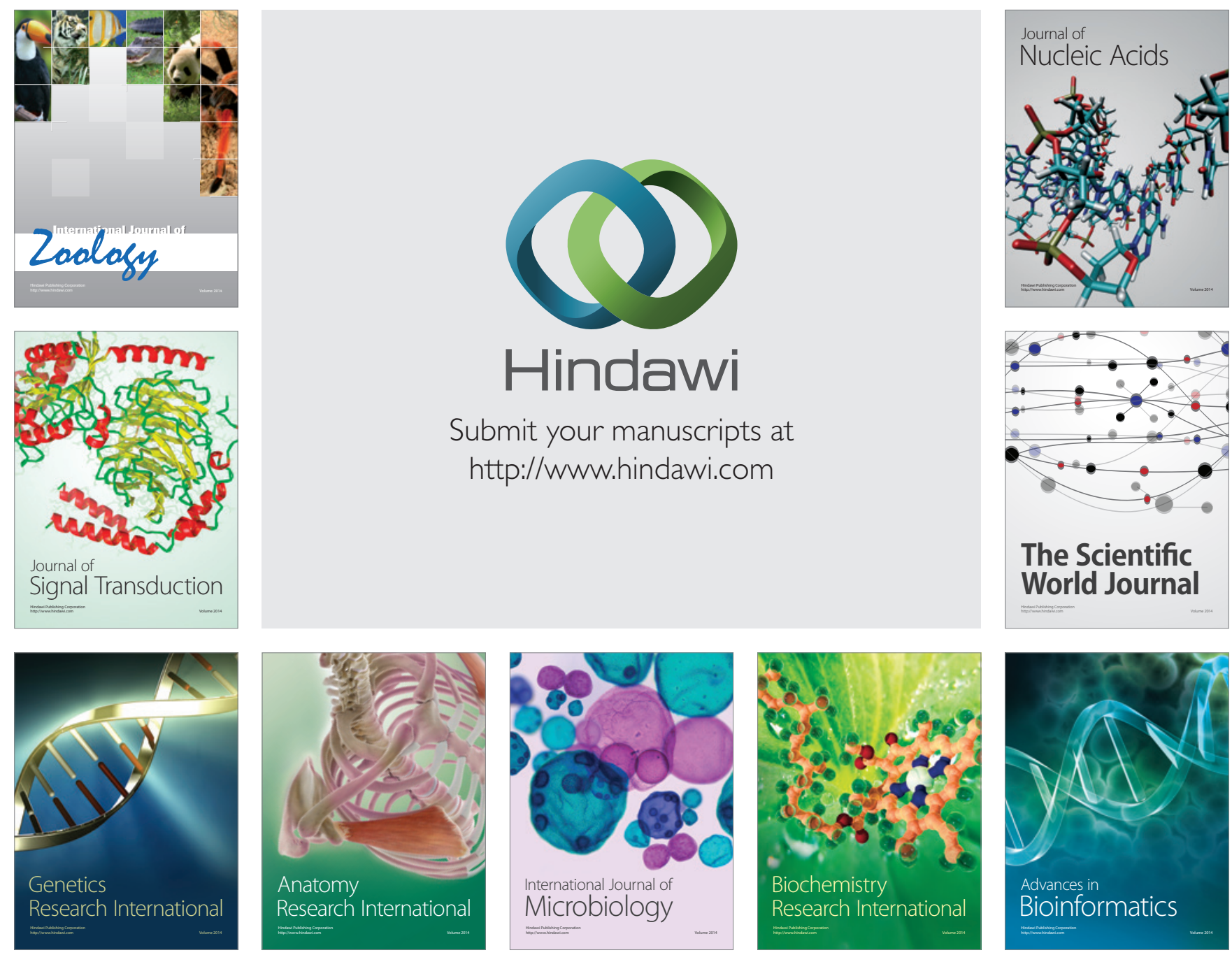

The Scientific World Journal
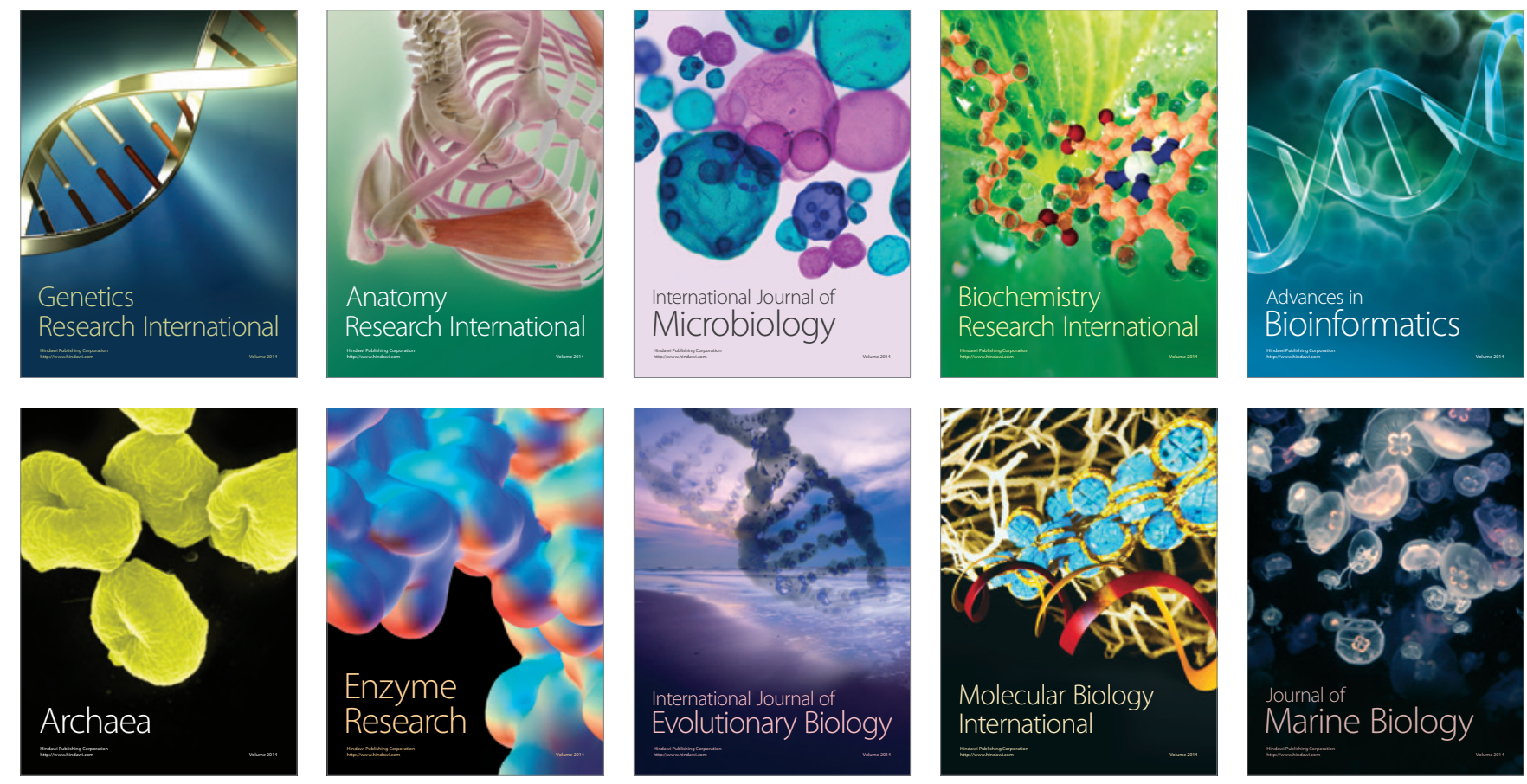